\title{
Scaling issues associated with using classroom technologies
}

\author{
Jason Foster, University of Toronto
}

\begin{abstract}
The modern engineering classroom has associated with it a myriad of educational technologies. Proponents of such technologies suggest that instructors avail themselves of technologies such as wikis, blogs, vidcasts, podcasts, screencasts, clickers, and backchannel instant messaging, in addition to managing their courses using the nigh ubiquitous online learning management systems. While the educational value of these technologies remains in question, their eventual inclusion into the classroom seems almost a certainty. Many of the discussions of educational technologies take place in the context of pilot studies or special-purpose initiatives. These contexts, where the ratio of students to teaching staff is generally small and where dedicated technical resources are usually available, do not mirror the usual Canadian undergraduate engineering classroom. This paper discusses the challenges faced when introducing education technologies into contexts where the number of students is much greater than the number of teaching staff, and where the resources to execute, support, and enhance the technologies are lacking.
\end{abstract}

